Article

\title{
Eosin Y-Catalyzed Visible-Light-Mediated Aerobic Transformation of Pyrazolidine-3-One Derivatives ${ }^{\dagger}$
}

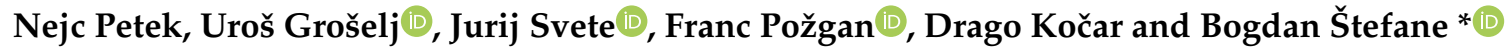 \\ Faculty of Chemistry and Chemical Technology, University of Ljubljana, Večna pot 113, \\ SI-1000 Ljubljana, Slovenia; nejc.petek@fkkt.uni-lj.si (N.P.); uros.groselj@fkkt.uni-lj.si (U.G.); \\ jurij.svete@fkkt.uni-lj.si (J.S.); franc.pozgan@fkkt.uni-lj.si (F.P.); drago.kocar@fkkt.uni-lj.si (D.K.) \\ * Correspondence: Bogdan.stefane@fkkt.uni-lj.si; Tel.: +386-1-4798560 \\ + Dedicated to Pierre H. Dixneuf for his outstanding contribution to organometallic chemistry and catalysis.
}

Received: 30 July 2020; Accepted: 12 August 2020; Published: 1 September 2020

\begin{abstract}
By utilizing an underexplored reactivity of N1-substituted pyrazolidine-3-ones, we developed a visible-light-induced aerobic oxidation of N1-substituted pyrazolidine-3-one derivatives yielding the corresponding azomethine imines. The resulting azomethine imines can be further reacted with ynones in situ under copper catalyzed [3 + 2] cycloaddition reaction conditions yielding the corresponding pyrazolo[1,2-a]pyrazoles in good yields. The methodology can be extended to other 1-aryl-substituted pyrazolidinones which undergo endocyclic oxidation deriving the corresponding pyrazolones as single products.
\end{abstract}

Keywords: pyrazolidine-3-ones; eosin Y; visible light; photoredox catalysis

\section{Introduction}

3-Oxopyrazolidin-1-ium-2-ides ( $N, N^{\prime}$-cyclic azomethine imines) were firstly described by Dorn et al. in 1968 [1,2]. Since then their synthetic potential has drawn significant interest as they can serve as synthons in straightforward and effective entries to pyrazolones and the related dinitrogen-fused heterocyclic derivatives [3-5]. Dinitrogen-fused analogues derived from $N, N^{\prime}$-cyclic azomethine imines were proven to display a range of biological activities [6] such as inhibition of human phosphodiesterase [7], inhibition of COX-2 [8], anti-alzheimer [9], and insecticidal activity [10]. The versatile reactivities of $N, N^{\prime}$-cyclic azomethine imines have been consistently explored, allowing the facile construction of a variety of dinitrogen-fused heterocyclic systems. Thus, owing to their inherent dipolar character, a range of dipolarophiles including olefins [11], alkynes [12], enones [13], isocyanides [14], and allenes [15] were subjected to [3+n] dipolar cyclization with $N, N^{\prime}$-cyclic azomethine imines to derive a range of fused dinitrogen-containing heterocycles. Interestingly, dimerization of $N, N^{\prime}$-cyclic azomethine imine under the UV-irradiation was observed by Rodina and Geissler et al., leading to the formation of a 1,5-diazabicycle [16,17].

Additionally to the annulation reaction pathways of $N, N^{\prime}$-cyclic azomethine imines, their direct functionalization afforded alternative modes of supplementing the library of dinitrogen-fused heterocycles. Based on the electrophilic character of the iminium moiety, nucleophilic additions to $N, N^{\prime}$-cyclic azomethine imines, including asymmetric Rh-catalyzed arylation [18], cyanation [19] Grignard reagent addition [20,21], and trifluoromethylation [22], have been introduced to functionalize dinitrogen heterocycles.

The use of visible-light-mediated photoredox catalysis as an environmentally friendly, sustainable, effective, and versatile method for the functionalization of a variety of systems such as relatively unreactive $\mathrm{C}-\mathrm{H}$ bonds adjacent to nitrogen or oxygen atoms, has been developed. The pioneering work in this research area, reported by the research groups of MacMillan [23-25], Yoon [26,27], 
Stephenson [28,29], and others [30-34], has shown that particular Ru and Ir complexes can act as visible-light photoredox catalysts capable of catalyzing a broad range of organic reactions. In contrast, other metal complexes such as Cu-based photocatalysts are emerging, offering not only economic and ecological advantages but also unique reactivity modes [35,36]. The use of organic dyes as photoredox catalysts [37] has been demonstrated to be a useful alternative to the inorganic photoredox catalysts that are expensive and sometimes toxic. Small organic molecules have also shown their activity towards the activation of the $\mathrm{O}_{2}$ molecule under visible light, and this synthetic strategy has already shown powerful applications in organic synthesis via $\mathrm{C}-\mathrm{H}$ bond activation and others [38-41]. Moreover, from an environmental point of view, oxygen $\left(\mathrm{O}_{2}\right.$ and air) represents an oxidant of choice, and its advantages include abundance, low cost, and production of water as a by-product [42,43].

Photooxidation of amine functionalities to amine-centered radical cations, displaying several modes of reactivity (Scheme 1A), has become a major approach to exploit the synthetic utility of photogenically produced amine radical cations [44]. As a part of our ongoing research on the reactivity and stereoselectivity of azomethine imines we hypothesized that N1-substituted pyrazolidine-3-ones could derive the azomethine imine functionality upon photooxidative conditions (Scheme 1B).

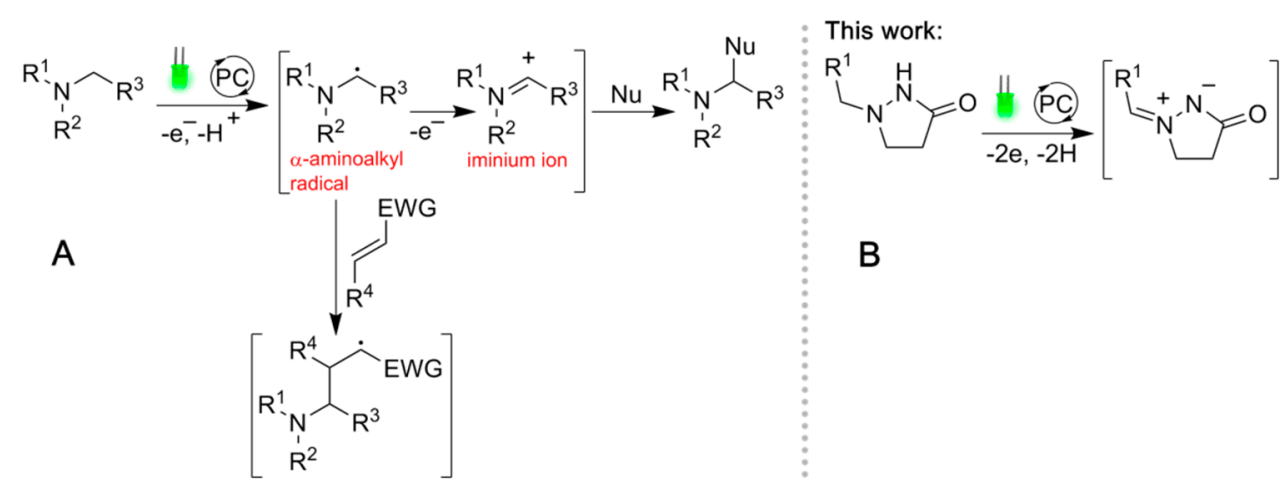

Scheme 1. Visible-light-induced $\mathrm{sp}^{3} \mathrm{C}-\mathrm{H}$ bond functionalization of $\alpha$-amino alkyl radical (A) and schematic representation of the transformation reported herein (B).

\section{Results and Discussion}

Herein, the development of visible-light-mediated aerobic transformation of N1-substituted pyrazolidine-3-one $\mathbf{1}$ derivatives yielding the corresponding azomethine imines $\mathbf{2}$ or pyrazolo[1,2-a]pyrazoles 3 and alternatively N1-substituted 1,2-dihydro-3H-pyrazol-3-ones 5 is disclosed (Scheme 2). Molecular oxygen or air serves as a sacrificial green and abounded oxidant in combination with eosin $\mathrm{Y}$ as the photocatalyst under blue LED irradiation.

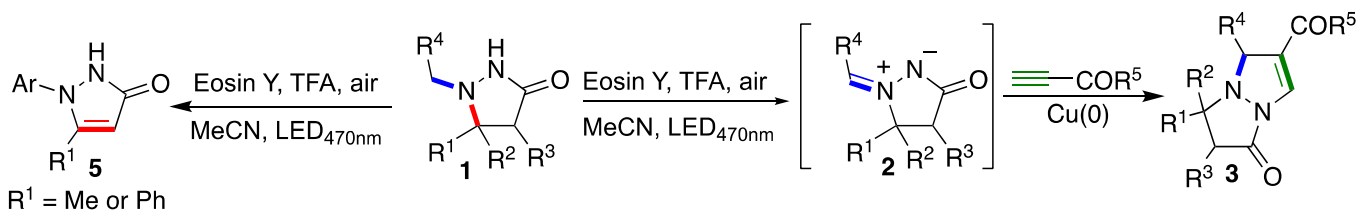

Scheme 2. Photocatalytic transformations of N1-substituted pyrazolidine-3-ones 1.

In the initial experiments, transformation of 1-(4-chlorobenzyl)-5,5-dimethylpirazolidin-3-one (1c) was conducted under different reaction conditions to yield the corresponding azomethine imine $\mathbf{2 c}$. Running the reaction in acetonitrile in the presence of $5 \mathrm{~mol} \%$ of eosin $\mathrm{Y}$, air, and trifluoroacetic acid (TFA, 2 equiv.) under LED irradiation $(470 \mathrm{~nm}$ ) for $60 \mathrm{~min}$ resulted in the formation of $2 \mathrm{c}$ in a $62 \%$ isolated yield (Table 1, entry 1). Optimization of the reaction conditions revealed, that addition of trifluoroacetic acid (TFA) was essential to achieve high conversions of $1 \mathrm{c}$ to $2 \mathrm{c}$ and to slow down the overoxidation of 2c, yielding the corresponding 4-chlorobenzaldehyde as a side product (Table 1, entry 13). Additionally, 
other acids were also employed such as oxalic acid, citric acid, and trichloroacetic acid resulting in lower conversions of the starting material 1c. Trifluoroacetic acid is most probably responsible for the protonation of the $\mathrm{N} 1$ nitrogen of azomethine imines 2 , which can be easily observed in the ${ }^{1} \mathrm{H}$ NMR spectra of compounds $\mathbf{2}$ in $\mathrm{CDCl}_{3}$. We presume that the protonated form of $\mathbf{2}$ is less prone for the photoinduced oxidation yielding the corresponding benzaldehydes under the applied reaction conditions. However, using other solvents than acetonitrile resulted in much lower yields of the corresponding azomethine imine $2 \mathrm{c}$, as determined by ${ }^{1} \mathrm{H}$ NMR analysis of the crude reaction mixture. When toluene was used as a solvent (Table 1 , entry 8) comparable results were observed after $0.5 \mathrm{~h}$ of irradiation at room temperature. The prolonged reaction times $(2-6 \mathrm{~h})$ result in diminished yields of $2 \mathrm{c}$ as 4-chlorobenzaldehyde is being formed as the major product. With the encouragement, the reaction was studied by varying the photocatalyst (Table 1, entries 9-12) however, eosin Y showed superior results and was selected as the most suitable photocatalyst for the transformation being studied. Reducing its loading to $2 \mathrm{~mol} \%$, (Table 1, entry 9) marginally decreased the yield of $\mathbf{2 c}$ and $5-\mathrm{mol} \%$ loading was necessary for short reaction times needed. The somewhat higher catalyst loading may be necessary due to the acidic reaction medium, where eosin $Y$ displays different absorption characteristics. According to the literature [27], Eosin $Y$ is expected to be quite unsuitable as a photocatalyst in acidic medium, however, we found that absorption (at $470 \mathrm{~nm}$ ) and fluorescence are still present and the absorption maximum moves towards the blue wavelengths (see Supplementary Materials). Increasing the quantity of TFA or dilution of reaction mixture only negligibly improved the yield of the product 2c. However, formation of $2 \mathrm{c}$ was observed only in traces when no irradiation was employed or no photocatalyst or oxygen was provided (Table 1, entry 19-21).

Table 1. Deviation from the standard reaction conditions for the transformation of pyrazolidine-3-one $1 \mathrm{c}$ to azomethine imine $2 \mathrm{c}$.

\begin{tabular}{|c|c|c|}
\hline Entry & Deviation from "Standard Conditions" & NMR Yield (\%) ${ }^{a}$ \\
\hline 1 & no deviation & $62^{b}$ \\
\hline 2 & $0.5 \mathrm{~h}$ & 36 \\
\hline 3 & DMSO- $d 6,0.5 \mathrm{~h}$ & trace \\
\hline 4 & $\mathrm{MeOH}, 0.5 \mathrm{~h}$ & 20 \\
\hline 5 & acetone, $0.5 \mathrm{~h}$ & trace \\
\hline 6 & THF, $0.5 \mathrm{~h}$ & trace \\
\hline 7 & DCM, $0.5 \mathrm{~h}$ & 20 \\
\hline 8 & toluene, $0.5 \mathrm{~h}$ & 35 \\
\hline 9 & $2 \mathrm{~mol} \% \operatorname{eosin} \mathrm{Y}$ & 50 \\
\hline 10 & $2 \mathrm{~mol}_{\%} \mathrm{MeMesAcrClO}_{4}$ & 38 \\
\hline 11 & $2 \mathrm{~mol} \% \mathrm{Ru}(\mathrm{bpy})_{3} \mathrm{Cl}_{2} \cdot 6 \mathrm{H}_{2} \mathrm{O}$ & 30 \\
\hline 12 & $2 \mathrm{~mol}^{\%} \operatorname{Ir}(\text { ppy })_{3}$ & 20 \\
\hline 13 & no acid added & $0^{\mathrm{c}}$ \\
\hline 14 & 4 equiv. TFA & 63 \\
\hline 15 & 2 equiv. TCA & 52 \\
\hline 16 & 2 equiv. Oxalic acid & 33 \\
\hline 17 & 2 equiv. Citric acid & trace \\
\hline 18 & $2.0 \mathrm{~mL}$ of $\mathrm{MeCN}$ & $63^{b}$ \\
\hline 19 & reaction carried out in the dark & trace \\
\hline 20 & reaction mixture purged with nitrogen & trace \\
\hline 21 & no catalyst added & trace \\
\hline
\end{tabular}

a Standard reaction conditions: starting compound 1c $(0.1 \mathrm{mmol})$, eosin Y-disodium salt (5 mol\%), MeCN $(1.0 \mathrm{~mL})$, trifluoroacetic acid (TFA) (2.0 equiv.), air, $25-30^{\circ} \mathrm{C}, 465-470 \mathrm{~nm}$ LED. Reaction time is $1 \mathrm{~h}$, unless noted otherwise. NMR yields were determined with 1,3,5-trimethoxybenzene as an internal standard; ${ }^{\mathrm{b}}$ Isolated yield of pure product is reported; ${ }^{\mathrm{c}} 4$-chlorobenzaldehyde is the major product. 
With the optimal reaction conditions established, starting compound 1c $(0.1 \mathrm{mmol})$, eosin Y-disodium salt (5 mol\%), MeCN (1.0 mL), TFA (2.0 equiv.), air, 25-30 ${ }^{\circ} \mathrm{C}, 465-470 \mathrm{~nm}$ LED, we then examined the substrate scope of the photoinduced oxidation of pyrazolidine-3-ones. As highlighted in Scheme 3, a range of 1-(benzyl)pirazolidin-3-ones were subjected to the optimized reaction conditions yielding the corresponding azomethine imines in good to moderate yields upon isolation. The reaction conditions tolerated a variety of substituents (electron-withdrawing and electron-donating) being present on the aromatic ring (Scheme 3, examples $\mathbf{2 a - 2 h}$ ). The C4-aminosubstituted pyrazolidin-3-one furnished the corresponding azomethine imine $\mathbf{2} \mathbf{j}$ in a reasonable $48 \%$ isolated yield. Structure variation in the benzylidene moiety can also be realized without major loss of reaction efficiency. The incorporation of the heteroaryl functionality such as pyridyl and furyl resulted in the formation of products $\mathbf{2 k}$ and $\mathbf{2 l}$ in reasonable yields. However, the alkylidene side chain proved to be more challenging. As demonstrated in Scheme 3 azomethine imine $\mathbf{2 m}$ was formed in situ with a good $70 \%$ yield and was found to be unstable during the isolation.

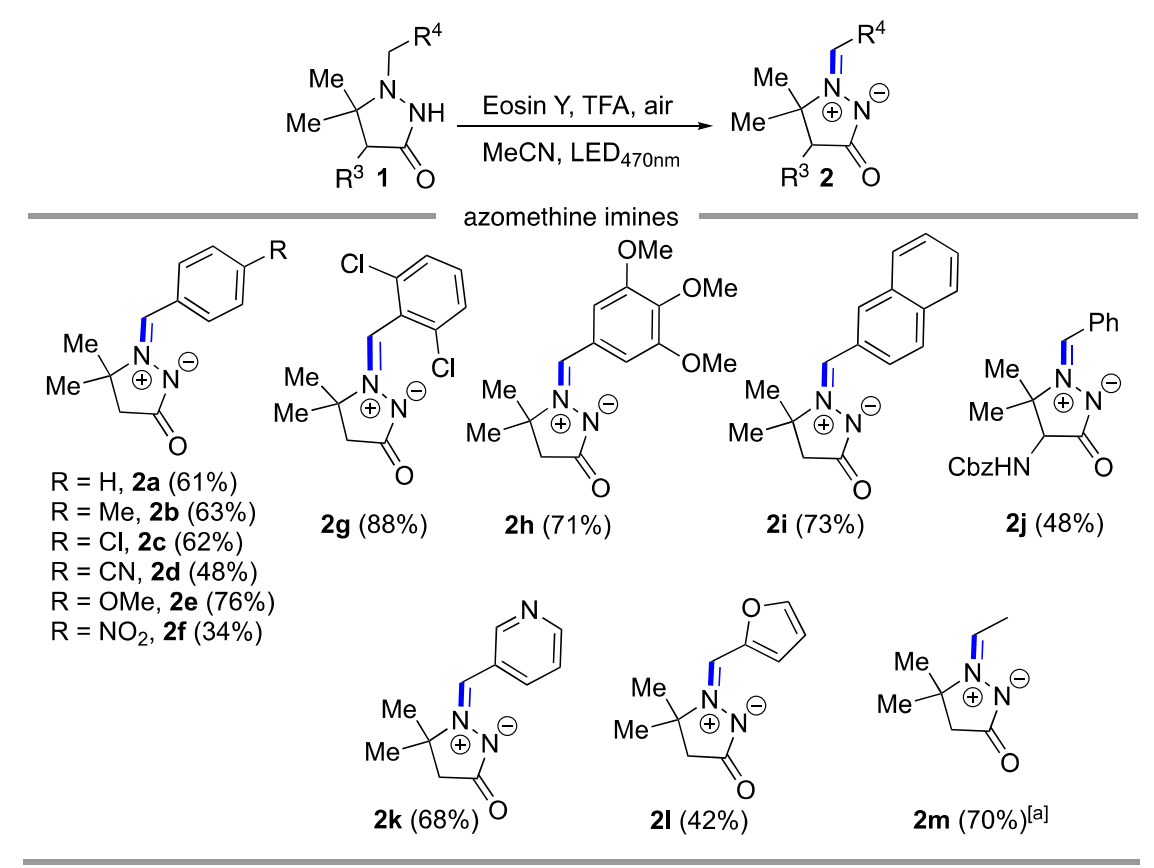

Scheme 3. Scope of azomethine imines 2. Standard reaction conditions: pyrazolidinone $\mathbf{1}$ (0.5 mmol), eosin Y-disodium salt $(5 \mathrm{~mol} \%), \mathrm{MeCN}(2.5 \mathrm{~mL}), \mathrm{TFA}$ (2.0 equiv.), air, $25-30{ }^{\circ} \mathrm{C}$, $465-470 \mathrm{~nm}$ LED. The reaction is running until starting material is consumed according to thin-layer chromatography (TLC), typically $1-5 \mathrm{~h}$. Isolated yields are reported. ${ }^{[a]}$ NMR yield, determined with 1,3,5-trimethoxybenzene as an internal standard, is given.

Experiments of the photoinduced oxidative formation of azomethine imines 2 (Scheme 3) revealed that the major side product in the reaction is the formation of the corresponding aldehydes, caused by rather slower oxidation of the former azomethine imines 2 under optimized reaction conditions. Accordingly, we turned our attention to the development of a one-pot protocol involving dual catalysis, namely, eosin $\mathrm{Y}$ photocatalyzed formation of azomethine imines followed by $\mathrm{Cu}$-catalyzed azomethine imine-alkyne cycloadditions. We anticipated that a fast click-reaction would prevent relatively slower overoxidation of $\mathbf{2}$ and therefore resulted in the formation of the corresponding cycloadducts 3 (Scheme 4). Applying the standard reaction conditions, eosin Y and TFA in acetonitrile in combination with $\mathrm{Cu}(0)$ proved to be the catalyst system of choice for formation of bicyclic product 3. In this manner we successfully developed a cascade protocol enabling the synthesis of an array of pyrazolo[1,2-a]pyrazoles 3 with good to excellent yields (Scheme 4). 


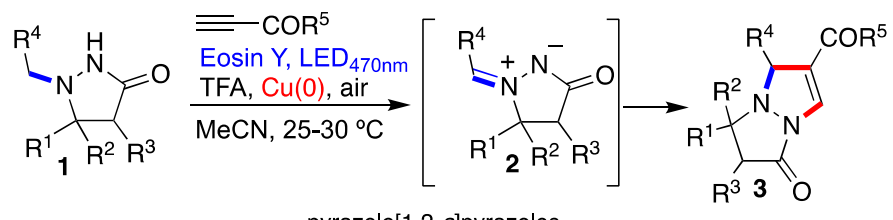<smiles>CC(=O)C1=CN2C(=O)CC(C)(C)N2C1c1ccc(Cl)cc1</smiles>

3a $(80 \%)$<smiles>CC(=O)C1=CN2C(=O)C(NC(=O)OCc3ccccc3)C(C(C)C)N2C1c1ccccc1</smiles>

3e $(52 \%)$<smiles>COC(=O)C1=CN2C(=O)CC(c3ccccc3)N2C1C</smiles>

3i (34\%)<smiles>COc1cc(C2C(C(C)=O)=CN3C(=O)CC(C)(C)N23)cc(OC)c1OC</smiles>

3b $(82 \%)$<smiles>CC(=O)C1=CN2C(=O)CC(C)(C)N2C1CCc1ccccc1</smiles>

$3 f(62 \%)$

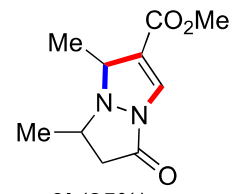

3j $(25 \%)$<smiles>CC(=O)C1=CN2C(=O)CC(C)(C)N2C1c1ccc([N+](=O)[O-])cc1</smiles>

3c $(73 \%)$<smiles>COC(=O)C1=CN2C(=O)CC(C)(C)N2C1C</smiles>

3g $(77 \%)$

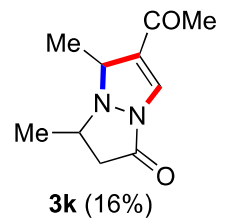

$\mathrm{O}_{2} \mathrm{~N}$<smiles>Cc1ccc(C2C(C(=O)C(C)NC(=O)OC(C)(C)C)=CN3C(=O)CC(C)(C)N23)cc1</smiles>

3d $(30 \%)$<smiles>CCC1C(C(C)=O)=CN2C(=O)CC(C)(C)N12</smiles>

3h $(51 \%)$

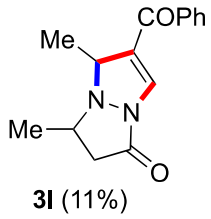

Scheme 4. Scope of pyrazolo[1,2-a]pyrazoles 3. Standard reaction conditions: pyrazolidinone $1(0.5 \mathrm{mmol})$, eosin Y-disodium salt (5 mol\%), MeCN (2.5 mL), TFA (2.0 equiv.), Cu(0) (20 mg), dipolarophile (1.5 eq.), air, $25-30{ }^{\circ} \mathrm{C}, 465-470 \mathrm{~nm}$ LED. The reaction is running until starting material is consumed according to TLC, usually in $1-5 \mathrm{~h}$. TFA is then neutralized with $\mathrm{K}_{2} \mathrm{HPO}_{4}$ (2 equiv.) and the reaction is stirred in the dark for additional $16 \mathrm{~h}$. Isolated yields are given.

Substituted azomethine imines 2 with variable substituents at the positions $\mathrm{C1}^{\prime}$ (alkyl and aryl substituents), $\mathrm{C} 4$ ( $\mathrm{H}$ or acylamino), and $\mathrm{C} 5(\mathrm{H}, \mathrm{Me}, i-\mathrm{Pr}$, or $\mathrm{Ph}$ ) were in situ generated by photoinduced oxidation of the corresponding pyrazolidine-3-one 1. In situ generated azomethine imines were reacted with ynones under copper powder-catalyzed cycloaddition reaction conditions yielding the corresponding pyrazolo[1,2-a]pyrazoles 3 . The relative configuration of compounds $3 \mathbf{d},\left[1^{*}\right] \mathbf{3} \mathbf{e},\left[2^{*}\right] \mathbf{3 i}-\mathbf{1}$ is in agreement with the literature data and was established by NOESY NMR experiments. The workup was comprised from the removal of the heterogeneous $\mathrm{Cu}(0)$ catalyst by filtration followed by the evaporation of the solvent. Purification by flash chromatography $\left(\mathrm{SiO}_{2}\right)$ provided pure isolated products. Good yields of azabicycles 3 were achieved with both electron-withdrawing (Scheme 4, 3a,c,d) and electron-donating groups (Scheme $4, \mathbf{3 b}$ ) on the benzene ring of azomethine imines. The reaction also worked reasonably well in the case of compounds with unactivated alkylpyrazolidinones (Scheme 4, $\mathbf{3 f}-\mathbf{3 h}$ ), however, longer side chains were proven to be more challenging, probably due to the low solubility of the starting material 1. Lower yields were obtained with the N1-alkyl, 5-methyl or phenyl substituted pyrazolidinones (Scheme 4, examples 3i-1). This could attribute to the partial endocyclic oxidation of the starting pyrazolidinones furnishing 1,2-dihydro-3H-pyrazol-3-ones 5 . Thus, examining the crude reaction mixture of $3 \mathbf{i}$ revealed the endocyclic oxidation side product with $\mathrm{m} / \mathrm{z} 189.1030$ (see Supplementary Materials) indicating the competitive (exo)endocyclic oxidation pathways.

Following the investigation of the C5-monosubstituted pyrazolidinones in the one-pot protocol (Scheme 4, examples 3i-1), we subsequently examined the utility of our method by exploring 1-aryl-substituted pyrazolidinones 4 (Scheme 5), which could only undergo endocyclic oxidation delivering the corresponding pyrazolones 5 . Reactions proceeded smoothly, delivering the desired 
products $\mathbf{5 a}-\mathbf{5} \mathbf{c}$ in $58-84 \%$ yields. Notably, electron-neutral and electron-deficient, $\mathbf{4 a}$ and $\mathbf{4 b}$, substrates were found to be less reactive and needed longer reaction times $(>24 \mathrm{~h})$ compared to electron-rich $4 \mathrm{c}$ which was noticeably more reactive. C5-monosabstituted (methyl and phenyl) pyrazolidinones $4 \mathbf{d}$ and $4 \mathbf{e}$ were also suitable substrates but delivered the corresponding pyrazolones in rather lower yields. The formation of 5 is believed to proceed through the intermediate $4^{\prime}$ which is generated via a single electron transfer (SET) event on N1 of pyrazolidinones 4 . The formed intermediate is then isomerized into pyrazolone 5 .
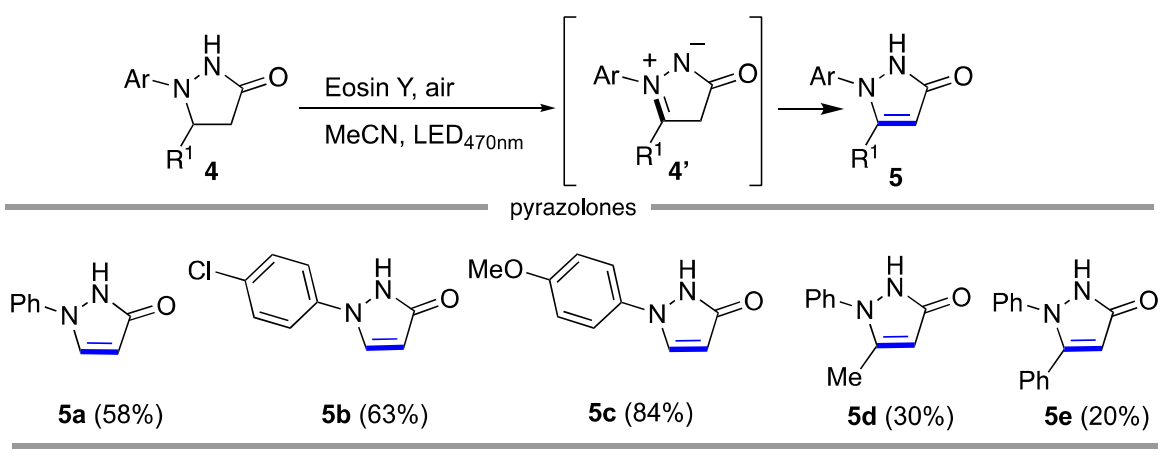

Scheme 5. Scope of pyrazolones 5. Standard reaction conditions: pyrazolidinone $\mathbf{1}(0.5 \mathrm{mmol})$, eosin Y-disodium salt (2 mol\%), $\mathrm{MeCN}(2.5 \mathrm{~mL})$, air, $25-30{ }^{\circ} \mathrm{C}, 465-470 \mathrm{~nm}$ LED. The reaction is complete in 24-48 h. NMR yields, determined with 1,3,5-trimethoxybenzene as an internal standard, are given.

It is well known that the organic dye eosin $\mathrm{Y}$ can exist in four different forms in solutions depending on $\mathrm{pH}$ of the media, namely, in the spirocyclic form, the neutral form, the monoanionic, and the dianionic form. The spirocyclic form contains an interrupted conjugation of the fluorone moiety and thus would be photocatalytically inactive upon visible-light irradiation. The neutral form, on the other hand, exhibits only weak fluorescence when irradiated with visible light [45]. In our case, absorption properties of eosin $\mathrm{Y}$ in acidic medium, i.e., acetonitrile and TFA (0.5M solution) were examined. As evident from the UV-vis spectra (see Supplementary Materials) of eosin $\mathrm{Y}$ in in the mixture of $\mathrm{MeCN} / \mathrm{CF}_{3} \mathrm{CO}_{2} \mathrm{H}(0.5 \mathrm{M})$, the organic dye possesses significant absorption at $465-470 \mathrm{~nm}$ of the LED irradiation. Cyclic voltammetry of $1 \mathrm{c}$ with ferrocene standard shows $E_{1 / 2}$ $\left(1 \mathrm{c}^{(\bullet+)} / 1 \mathrm{c}\right)=0.73 \mathrm{~V}$ vs. SCE, which allows it to be oxidized by ${ }^{3} \mathrm{EY}^{*}\left(E_{1 / 2}\left({ }^{3} \mathrm{EY}^{*} / \mathrm{EY}^{(\bullet-)}\right)=0.83 \mathrm{~V}\right.$ vs. SCE [46] (see Supplementary Materials).

When the reaction was performed under standard reaction conditions-(starting compound 1c ( $0.1 \mathrm{mmol})$, eosin Y-disodium salt ( $5 \mathrm{~mol} \%), \mathrm{MeCN}(1.0 \mathrm{~mL})$, TFA (2.0 equiv.), air, $25-30^{\circ} \mathrm{C}, 465-470 \mathrm{~nm}$ LED) — in the presence of a classical radical inhibitor (TEMPO), the formation of TEMPO-pyrazolone conjugate $\left(\mathrm{m} / \mathrm{z}\left(\mathrm{MH}^{+}\right) ; 349.2247\right.$ corresponding to $\left.\mathrm{C}_{21} \mathrm{H}_{32} \mathrm{ClN}_{3} \mathrm{O}_{2}\right)$ was detected by HRMS analysis in the crude reaction mixture. In absence of light irradiation (reaction running in the dark) only traces of product were observed, whereas in the absence of the photocatalyst no product was formed, which suggests the necessity of the photoredox catalyst and visible light for the reaction to occur. When the reaction was carried out under nitrogen atmosphere, only $5 \%$ of $2 \mathrm{c}$ was formed, proving the requirement of oxygen for the reaction to accrue. From the above controlled experiments and the literature reports [39,44,47-49], the following plausible radical cation cascade reaction pathway has been suggested (Scheme 6). Initially, under visible-light irradiation, eosin $\mathrm{Y}\left(\mathrm{EY}\right.$ ) is excited to ${ }^{1} \mathrm{EY}^{*}$ which moves to its more stable ${ }^{3} \mathrm{EY}^{*}$ through intersystem crossing (ISC) [50]. Subsequently, the excited state transforms pyrazolidinone $1 \mathrm{c}$ by SET into a nitrogen radical cation, with the concomitant reduction of ${ }^{3} \mathrm{EY}^{*}$ in to the radical anion $\mathrm{EY}^{(\bullet-)}$, which is afterwards oxidized by molecular oxygen regenerating the photocatalyst EY. On the other hand, deprotonation of the nitrogen radical cation generates the $\alpha$-amino radical, that is further oxidized to the azomethine imine $2 \mathbf{c}$ by $\mathrm{HO}_{2}{ }^{(\bullet)}$ species. The generated 
azomethine imine $2 \mathbf{c}$ subsequently enters copper catalyzed [3+2] cycloaddition reaction catalytic cycle furnishing pyrazolo[1,2-a]pyrazole $3 a$.

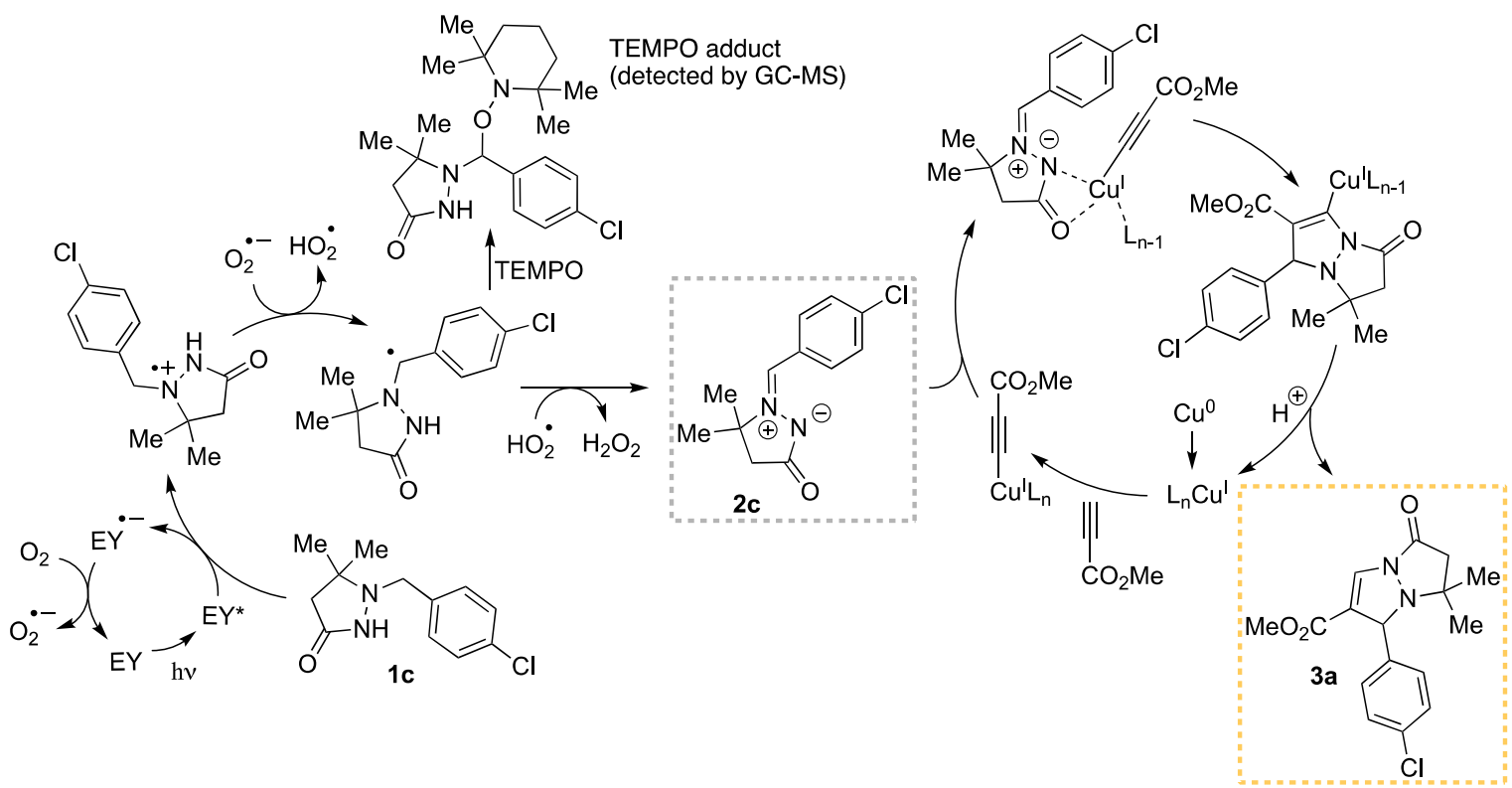

Scheme 6. A plausible reaction mechanism for the visible-light-mediated synthesis of 2 and 3.

\section{Materials and Methods}

\subsection{General}

Reactions were carried out in a commercially available SynLED Parallel Photoreactor (465-470 nm LEDs, $130-140 \mathrm{~lm}$, Sigma-Aldrich, St. Louis, MO, USA), which operates at approximately $25-30^{\circ} \mathrm{C}$. The NMR spectra were recorded in deuterated solvents with $\mathrm{Me}_{4} \mathrm{Si}$ as the internal standard on a Bruker Avance DPX 300 (Bruker, Billerica, MA, USA) and Bruker Avance III UltraShield 500 (Bruker, Billerica, MA, USA) plus instruments at 300 and $500 \mathrm{MHz}$ for ${ }^{1} \mathrm{H}$ and at 75.5 and $126 \mathrm{MHz}$ for ${ }^{13} \mathrm{C}$ nuclei, respectively. Data for ${ }^{1} \mathrm{H}$ NMR are reported as chemical shifts $(\delta)$ in ppm, integration, multiplicity ( $\mathrm{s}=$ singlet, $\mathrm{d}=$ doublet, $\mathrm{t}=$ triplet, $\mathrm{q}=$ quartet, $\mathrm{m}=$ multiplet $)$, coupling constant and assignment. Data for ${ }^{13} \mathrm{C}$ are reported as chemical shift $(\delta)$ in ppm. Mass spectra were recorded on Agilent 6224 Accurate Mass TOF LC/MS spectrometer (Agilent Technologies, Santa Clara, CA, USA) and IR spectra on a Bruker FTIR Alpha Platinum spectrophotometer (Bruker, Billerica, MA, USA). Melting points were determined on a Kofler hot-stage microscope and on a MPA100 OptiMelt automated melting point system (Stanford Research Systems, Sunnyvale, CA, USA). Thin-layer chromatography (TLC) was performed on aluminum backed silica plates (0.2 mm, 60 F254, Sigma-Aldrich, St. Louis, MO, USA). Visualization of TLC ( $254 \mathrm{~nm}$, Camag, Muttenz, Switzerland) was performed by fluorescence quenching or with potassium permanganate stains. Flash column chromatography (FC) and column chromatography (CC) were performed on silica gel (particle size: 35-70 $\mu \mathrm{m}$, Sigma-Aldrich, St. Louis, MO, USA). Commercially available compounds were used without further purification. Compounds 1 were prepared according to the established literature procedures (see Supplementary Materials).

\subsection{General Procedure for the Synthesis of Azomethine Imines $\mathbf{2}$}

In a 5 -mL vial, starting compound $(0.5 \mathrm{mmol})$ and eosin Y-disodium salt $(5 \mathrm{~mol} \%)$ are dissolved in $\mathrm{MeCN}(2.5 \mathrm{~mL}$ ). TFA (2.0 equiv.) is added and the solution irradiated with blue light under air on SynLED Photoreactor for 1-5 h until consumption of starting material is complete according to TLC. Prolonged reaction times result in diminished yields. After evaporation of the solvent, the NMR yield 
is determined by addition of 1,3,5-trimethoxybenzene as standard. Compounds 2 were isolated by FC on silica with $10 \%$ solid $\mathrm{NaHCO}_{3}(\mathrm{EtOAc}$, EtOAc/MeOH).

\subsection{General Procedure for the Synthesis of pyrazolo[1,2-a]pyrazoles 3}

In a 5 -mL vial, starting compound $(0.5 \mathrm{mmol})$ and eosin Y-disodium salt $(5 \mathrm{~mol} \%)$ are dissolved in $\mathrm{MeCN}(2.5 \mathrm{~mL})$. TFA (2.0 equiv.), copper powder ( $<10$ microns, $20 \mathrm{mg}$ ) and dipolarophile (1.5 eq.) are added and the solution irradiated with blue light under air on SynLED Photoreactor for $1-5 \mathrm{~h}$ until consumption of starting material is complete according to TLC. $\mathrm{K}_{2} \mathrm{HPO}_{4}$ (2 equiv.) is added and the mixture stirred in the dark for an additional $16 \mathrm{~h}$. Products 3 are isolated by CC (EtOAc/hexanes).

\subsection{General Procedure for the Synthesis of pyrazolones $\mathbf{5}$}

In a 5 -mL vial, starting compound $(0.5 \mathrm{mmol})$ and eosin Y-disodium salt $(2 \mathrm{~mol} \%)$ are dissolved in MeCN (2.5 mL). The solution is irradiated with blue light under air on SynLED Photoreactor overnight (18-24 h). After evaporation of the solvent, the NMR yield is determined by addition of 1,3,5-trimethoxybenzene as standard. Products $\mathbf{5}$ can be isolated by FC (EtOAc/hexanes).

\section{Conclusions}

In summary, an efficient and mild visible-light-mediated aerobic transformation of pyrazolidine-3-one derivatives is disclosed. The methodology enables the generation of azomethine imines as versatile intermediates. The photoredox cycle is merged with copper powder catalyzed $[3+2]$ cycloaddition reaction yielding the corresponding cycloadducts in a one-pot synthetic protocol. The complexity of the product delivered under this mild reaction conditions makes these new methods an attractive alternative for the formation of functionalized pyrazolo[1,2-a]pyrazoles. The methodology was also applied to 1-aryl-substituted pyrazolidinones yielding pyrazolones in yields up to $84 \%$.

Supplementary Materials: The following are available online at http://www.mdpi.com/2073-4344/10/9/981/s1: 1. Cyclic voltammograms, 2. Absorption spectroscopy, 3. Mass spectrometry, 4. Characterization of compounds 1-5, 5. 1H and 13C NMR spectra of novel compounds 1, 2 and 3.

Author Contributions: Conceptualization, U.G., J.S., F.P. and B.Š.; methodology, N.P. and B.Š.; software, U.G., N.P., J.S., F.P., and B.Š.; validation, U.G., N.P., J.S., F.P., and B.Š.; formal analysis, N.P., D.K., and B.Š.; investigation, N.P. and B.Š.; resources, N.P., D.K., and B.Š.; data curation, U.G., N.P., J.S., F.P., D.K. and B.Š.; writing—original draft preparation, N.P. and B.Š.; writing-review and editing, N.P., U.G., J.S., F.P., D.K. and B.S.; visualization, N.P. and B.Š.; supervision, B.Š.; project administration, B.Š.; funding acquisition, J.S., U.G., F.P. and B.Š. All authors have read and agreed to the published version of the manuscript.

Funding: This research was funded by the Slovenian Research Agency through grants P1-0179 and P1-0503.

Conflicts of Interest: The authors declare no conflict of interest.

\section{References}

1. Dorn, H.; Otto, A. Über die Reaktion von Pyrazolidon-(3) mit Carbonylverbindungen. Chem. Ber. 1968, 101, 3287-3301. [CrossRef]

2. Dorn, H.; Otto, A. Syntheses by Means of 1-Alkylidene- and 1-(Arylalkylidene)-3-pyrazolidone $N, N$-Betaines, a New Type of Stable Azomethine Imine. Angew. Chem. Int. Ed. 1968, 7, 214-215. [CrossRef]

3. Schantl, J.G. Advances in Heterocyclic Chemistry; Elsevier Inc.: San Diego, CA, USA, 2010; Volume 99, p. 185.

4. Najera, C.; Sansano, J.M.; Yus, M. 1,3-Dipolar cycloadditions of azomethine imines. Org. Biomol. Chem. 2015, 13, 8596-8636. [CrossRef] [PubMed]

5. Belskaya, N.P.; Bakulev, V.A.; Fan, Z. Synthesis and (3+2) cycloaddition reactions of $N, N^{\prime}$-and $C, N$-cyclic azomethine imines. Chem. Heterocycl. Compd. 2016, 52, 627-636. [CrossRef]

6. Ternansky, R.J.; Draheim, S.E.; Pike, A.J.; Counter, F.T.; Eudaly, J.A.; Kasher, J.S. Structure-activity relationship within a series of pyrazolidinone antibacterial agents. 2. Effect of side-chain modification on in vitro activity and pharmacokinetic parameters. J. Med. Chem. 1993, 36, 3224-3229. [CrossRef] [PubMed] 
7. Huang, Z.; Liu, S.; Zhang, L.; Salem, M.; Greig, G.M.; Chan, C.C.; Natsumeda, Y.; Noguchi, K. Preferential inhibition of human phosphodiesterase 4 by ibudilast. Life Sci. 2006, 78, 2663-2668. [CrossRef]

8. Gautam, S.; Rani, S.; Aldossary, S.A.; Saeedan, A.S.; Ansari, M.N.; Kaithwas, G. Effects of phenidone (DuCLOX-2/5 inhibitor) against $N$-methyl- $N$-nitrosourea induced mammary gland carcinoma in albino rats. Toxicol. Appl. Pharmacol. 2018, 351,57-63. [CrossRef]

9. Kosower, E.; Hershkowitz, E. 1,5-Diazabicyclo[3,3,0]octanediones and Pharmaceutical Compositions Containing Them. Isr. Patent ISXXAQ IL 94658, 7 October 1994.

10. Kosower, E.M.; Radkowskyl, A.R.; Fairlambz, A.H.; Croft, S.L.; Neal, R.A. Bimane cyclic esters, possible stereologues of trypanothione as antitrypanosomal agents. Bimanes 29. Eur. J. Med. Chem. 1995, 30, 659-671. [CrossRef]

11. Tong, T.M.; Soeta, T.; Suga, T.; Kawamoto, K.; Hayashi, Y.; Ukaji, Y. Formal Total Synthesis of Manzacidin C Based on Asymmetric 1,3-Dipolar Cycloaddition of Azomethine Imines. J. Org. Chem. 2017, 82, 1969-1976. [CrossRef]

12. Shen, S.; Yang, Y.; Duan, J.; Jia, Z.; Liang, J. Solvent incorporated sequential [3+2] annulation/substitution reaction of azomethine imines and propargyl sulfur ylide. J. Org. Biomol. Chem. 2018, 16, 1068-1072. [CrossRef]

13. Wang, M.; Huang, Z.; Xu, J.; Chi, Y.R. N-Heterocyclic Carbene-Catalyzed [3+4] Cycloaddition and Kinetic Resolution of Azomethine Imines. J. Am. Chem. Soc. 2014, 136, 1214-1217. [CrossRef] [PubMed]

14. Du, J.; Xu, X.; Li, Y.; Pan, L.; Liu, Q. [3+3]-Cycloaddition Reactions of $\alpha$-Acidic Isocyanides with 1,3-Dipolar Azomethine Imines. Org. Lett. 2014, 16, 4004-4007. [CrossRef] [PubMed]

15. Meng, W.; Zhao, H.-T.; Nie, J.; Zheng, Y.; Fu, A.; Ma, J.-A. Allenoate-derived 1,5-, 1,7-, and 1,9-zwitterions as highly versatile coupling-partners for phosphine-triggered cycloaddition reactions. Chem. Sci. 2012, 3, 3053-3057. [CrossRef]

16. Rodina, L.; Verzhba, O.A.; Korobitsyna, I.K. Photochromism in a series of azomethinimines based on 4-phenyl-1,2,4-triazoline-3,5-dione. Chem. Heterocycl. Comp. 1983, 19, 1345. [CrossRef]

17. Geissler, G.; Fust, W.; Krüger, B.; Tomaschewski, G. Azomethinimine. VII. Photochemisches und thermisches Verhalten azarylsubstituierter Pyrazolidon-(3)-azomethinimine. Adv. Synth. Catal. 1983, 325, 205-210. [CrossRef]

18. Shintani, R.; Soh, Y.; Hayashi, T. Rhodium-Catalyzed Asymmetric Arylation of Azomethine Imines. Org. Lett. 2010, 12, 4106-4109. [CrossRef]

19. Wang, H.Y.; Zheng, C.W.; Chai, Z.; Zhang, J.X.; Zhao, G. Asymmetric cyanation of imines via dipeptide-derived organophosphine dual-reagent catalysis. Nat. Commun. 2016, 7, 12720-12729. [CrossRef]

20. Rutjes, F.P.J.T.; Udding, J.H.; Hiemstra, H.; Speckamp, W.N. Preparation od Cyclic $\alpha$-Hydrazino Acids through N-Acylhydrazonium Intermediates. Heterocycles 1992, 33, 81-85.

21. Kirar, E.P.; Drev, M.; Mirnik, J.; Grošelj, U.; Golobič, A.; Dahmann, G.; Požgan, F.; Štefane, B.; Svete, J. Synthesis of 3D-Rich Heterocycles: Hexahydropyrazolo[1,5-a]pyridin-2(1H)-ones and Octahydro-2H-2a,2a1diazacyclopenta[cd]inden-2-ones. J. Org. Chem. 2016, 81, 8920-8933. [CrossRef]

22. Kawai, H.; Kusuda, A.; Nakamura, S.; Shiro, M.; Shibata, N. Catalytic Enantioselective Trifluoromethylation of Azomethine Imines with Trimethyl(trifluoromethyl)silane. Angew. Chem. Int. Ed. 2009, 48, 6324-6327. [CrossRef]

23. Pirnot, M.T.; Rankic, D.A.; Martin, D.B.C.; MacMillan, D.W.C. Photoredox Activation for the Direct $\beta$-Arylation of Ketones and Aldehydes. Science 2013, 339, 1593-1596. [CrossRef] [PubMed]

24. Nicewicz, D.A.; MacMillan, D.W.C. Merging Photoredox Catalysis with Organocatalysis: The Direct Asymmetric Alkylation of Aldehydes. Science 2008, 322, 77-80. [CrossRef] [PubMed]

25. Nagib, D.A.; MacMillan, D.W.C. Trifluoromethylation of arenes and heteroarenes by means of photoredox catalysis. Nature 2011, 480, 224-228. [CrossRef] [PubMed]

26. Ischay, M.A.; Anzovino, M.E.; Du, J.; Yoon, T.P. Efficient Visible Light Photocatalysis of [2+2] Enone Cycloadditions. J. Am. Chem. Soc. 2008, 130, 12886-12887. [CrossRef] [PubMed]

27. Du, J.; Yoon, T.P. Crossed Intermolecular [2+2] Cycloadditions of Acyclic Enones via Visible Light Photocatalysis. J. Am. Chem. Soc. 2009, 131, 14604-14605. [CrossRef]

28. Dai, C.; Narayanam, J.M.R.; Stephenson, C.R.J. Visible-light-mediated conversion of alcohols to halides. Nat. Chem. 2011, 3, 140-145. [CrossRef] 
29. Narayanam, J.M.R.; Tucker, J.W.; Stephenson, C.R.J. Electron-Transfer Photoredox Catalysis: Development of a Tin-Free Reductive Dehalogenation Reaction. J. Am. Chem. Soc. 2009, 131, 8756-8757. [CrossRef]

30. Zou, Y.-Q.; Lu, L.-Q.; Fu, L.; Chang, N.-J.; Rong, J.; Chen, J.-R.; Xiao, W.-J. Visible-Light-Induced Oxidation/[3+2] Cycloaddition/Oxidative Aromatization Sequence: A Photocatalytic Strategy To Construct Pyrrolo[2,1-a]isoquinolines. Angew. Chem. Int. Ed. 2011, 50, 7171-7175. [CrossRef]

31. Zou, Y.-Q.; Chen, J.-R.; Liu, X.-P.; Lu, L.-Q.; Davis, R.-L.; Jørgensen, K.A.; Xiao, W.-J. Highly Efficient Aerobic Oxidative Hydroxylation of Arylboronic Acids: Photoredox Catalysis Using Visible Light. Angew. Chem. Int. Ed. 2012, 51, 784-788. [CrossRef]

32. Fan, W.; Li, P. Visible-Light-Mediated 1,2-Acyl Migration: The Reaction of Secondary Enamino Ketones with Singlet Oxygen. Angew. Chem. Int. Ed. 2014, 53, 12201-12204. [CrossRef]

33. Zhu, S.; Das, A.; Bui, L.; Zhou, H.; Curran, D.P.; Rueping, M. Oxygen Switch in Visible-Light Photoredox Catalysis: Radical Additions and Cyclizations and Unexpected C-C-Bond Cleavage Reactions. J. Am. Chem. Soc. 2013, 135, 1823-1829. [CrossRef] [PubMed]

34. Sun, H.; Yang, C.; Gao, F.; Li, Z.; Xia, W. Oxidative C-C Bond Cleavage of Aldehydes via Visible-Light Photoredox Catalysis. Org. Lett. 2013, 15, 624-627. [CrossRef] [PubMed]

35. Riser, O. Shining Light on Copper: Unique Opportunities for Visible-Light-Catalyzed Atom Transfer Radical Addition Reactions and Related Processes. Acc. Chem. Res. 2016, 49, 1990-1996. [CrossRef] [PubMed]

36. Hossain, A.; Bhattacharyya, A.; Reiser, O. Copper's rapid ascent in visible-light photoredox catalysis. Science 2019, 364, 450-461. [CrossRef] [PubMed]

37. Romero, N.; Nicewicz, D.A. Organic Photoredox Catalysis. Chem. Rev. 2016, 116, 10075-10166. [CrossRef]

38. Nicewicz, D.A.; Nguyen, M.T. Recent Applications of Organic Dyes as Photoredox Catalysts in Organic Synthesis. ACS Catal. 2014, 4, 355-360. [CrossRef]

39. Neumann, M.; Füldner, S.; König, B.; Zeitler, K. Metal-Free, Cooperative Asymmetric Organophotoredox Catalysis with Visible Light. Angew. Chem. Int. Ed. 2011, 50, 951-954. [CrossRef]

40. Romero, N.A.; Margrey, K.A.; Tay, N.E.; Nicewicz, D.A. Site-selective arene C-H amination via photoredox catalysis. Science 2015, 349, 1326-1330. [CrossRef]

41. Ghosh, I.; Ghosh, T.; Bardagi, L.J.; König, B. Reduction of aryl halides by consecutive visible light-induced electron transfer processes. Science 2014, 346, 725-728. [CrossRef]

42. Shi, Z.; Zhang, C.; Tang, C.; Jiao, N. Recent advances in transition-metal catalyzed reactions using molecular oxygen as the oxidant. Chem. Soc. Rev. 2012, 41, 3381-3430. [CrossRef]

43. Wang, D.; Weinstein, A.B.; White, P.B.; Stahl, S.S. Ligand-Promoted Palladium-Catalyzed Aerobic Oxidation Reactions. Chem. Rev. 2018, 118, 2636-2679. [CrossRef] [PubMed]

44. Hu, J.; Wang, J.; Nguyen, T.H.; Zheng, N. The chemistry of amine radical cations produced by visible light photoredox catalysis. Beilstein J. Org. Chem. 2013, 9, 1977-2001. [CrossRef] [PubMed]

45. Majek, M.; Filace, F.; Jacobi von Wangelin, A. On the mechanism of photocatalytic reactions with eosin Y. Beilstein J. Org. Chem. 2014, 10, 981-989. [CrossRef]

46. Lazarides, T.; McCormick, T.; Du, P.; Luo, G.; Lindley, B.; Eisenberg, R. Making Hydrogen from Water Using a Homogeneous System Without Noble Metals. J. Am. Chem. Soc. 2009, 131, 9192-9194. [CrossRef] [PubMed]

47. Xie, J.; Jin, H.; Xu, P.; Zhu, C. When C-H bond functionalization meets visible-light photoredox catalysis. Tetrahedron Lett. 2014, 55, 36-48. [CrossRef]

48. Nishino, M.; Hirano, K.; Satoh, T.; Miura, M. Copper-Catalyzed Oxidative Direct Cyclization of $\mathrm{N}$-Methylanilines with Electron-Deficient Alkenes Using Molecular Oxygen. J. Org. Chem. 2011, 76, 6447-6451. [CrossRef]

49. Ju, X.; Li, D.; Li, W.; Yu, W.; Bian, F. The Reaction of Tertiary Anilines with Maleimides under Visible Light Redox Catalysis. Adv. Synth. Catal. 2012, 354, 3561-3567. [CrossRef]

50. Shimidzu, T.; Iyoda, T.; Koide, Y. An advanced visible-light-induced water reduction with dye-sensitized semiconductor powder catalyst. J. Am. Chem. Soc. 1985, 107, 35-41. [CrossRef]

(C) 2020 by the authors. Licensee MDPI, Basel, Switzerland. This article is an open access article distributed under the terms and conditions of the Creative Commons Attribution (CC BY) license (http://creativecommons.org/licenses/by/4.0/). 